\title{
白アリ防除家屋における食餌性クロルデン量の増加*1
}

(平成元年 10 月 9 日受理)

$\begin{array}{lll}\text { 小西良昌*2 } & \text { 薬師寺積*2 } & \text { 田口修三*2 } \\ \text { 西宗高弘*2 }^{* \text { 田中凉一² }} & \end{array}$

\section{Increase of Dietary Chlordane Intake in Homes Treated for Termite Control (Studies on the Route of Chlordane Contamination to Humans. II)}
Yoshimasa Konishi*2, Tsumoru YakUShiji², Shuzo TAGUCHI ${ }^{* 2}$, Takahiro NishimunE* and Ryoichi TANAKA*2

(*20saka Prefectural Institute of Public Health: 1-3-69, Nakamichi, Higashinari-ku, Osaka, Japan)

\begin{abstract}
Dietary intakes of chlordane ( $\mathrm{CHL}$ ) were investigated in order to clarify the degree of contribution of the routes of human exposure. Seventy-five daily diet samples from 25 housewives living in the Kinki area and 25 samples from 25 housewives living in Ebetsu City, Hokkaido, were analyzed for CHL complex (6 compounds) and 4 other organochlorine compounds. Mean intake of $\mathrm{CHL}$ in the Kinki area, approximately $2 \mu \mathrm{g} / \mathrm{day}$, was higher than those of DDT, DDE and HCB. Intakes of all of the CHL complex in the Kinki area were significantly higher than those in Ebetsu, though other organochlorines were in the same ranges. Close and statistically significant relationships between dietary intakes of chemicals and fishes were observed for all of the pollutants analyzed in non-CHL-treated homes, confirming the results reported by others. In the CHL-treated homes, however, intake of $\mathrm{CHL}$ complex were not related to the amount of fish intake even though intakes of DDT, DDE and HCB were, again, related to that of fishes. The significance of the differences of chemical intakes between CHL-treated and non-treated homes was examined by using student's $t$ test. No significant change was observed for DDT, DDE, HCB or HCE between these 2 groups. Intakes of CHL complex for treated homes were, however, remarkably higher than those of non-treated homes. Moreover, the chromatographic patterns of $\mathrm{CHL}$ complex in the diet from treated homes were very specific, indicating that relatively volatile components in technical $\mathrm{CHL}$ might be absorbed by certain foodstuffs. These results show that human exposure to CHL in nontreated homes depends mainly on the intakes of fishes, similar to the exposure to PCB and DDT. On the other hand, in a CHL-treated homes, participation of some other route, which could be a major source of human exposure, was indicated.
\end{abstract}

(Received October 9, 1989)

Key words： クロルデン chlordane；有機塩素系化合物 organochlorine compounds；白アリ防除 termite control；搨取量 dietary intake；1 日攝取量 daily intake

\section{緒言}

Chlordane (以下 CHL と略す) は, 日本では白アリ防 除に多用され，その使用量は 1970 年代前半から徐々に 增加し続け, 通産省統計によると 1986 年の使用禁止時

*1クロルデンのヒト污染経路に関する研究（第 2 報）

*2 大阪府立公衆衛生研究所：大阪市東成区中道 1-3-69
点では約 1 万 5 千トンに達した。この量は, PCB の懪境 放出推定量とほほ等し(1), 2). BHC (HCH), DDT などの 有機塩素系農薬やPCB は, 数多くの調查研究によって, ヒト污染経路が解放系環境にある魚介類が中心であるこ とが明らかにされている。これに対し，CHLは主に床下 に散布されることから，閉鎖系での直接的な七卜污染経 路をむつことが予想される. 事実, 白アリ防除家屋居住 
者の母乳污染調查を行なったところ，CHL 濃度が居住 年数 $5 \sim 6$ 年まで徐々に上昇し，対照に比へて有意に高 かっだ!. その主原因は，床下やCHL 処理木材から揮散 するCHL エアロソルの吸入であると考えられていた.

著者らは，母乳污染経路解明の試みの一つとして, 1985 年から 3 年間にわたり, 陰暿方式による食鲰由来 の摄取量調查を行った．前報において，1 年目の分析結 果をまとめ，CHLの食锃由来摄取量が PCB，DDT に匹 敬することと，その供給源は PCB, DDT と同様に魚介類 であることを述べだ。. 本報では，2 年目以降の調查結果 について，白アリ防除家庭と無処理家庭の食郋中 CHL を比较したところ，両者間に有意の差を認めたのでその 概要を報告するととるに，摄取量の地域差（近畿対北海 道）についても検討した。

\section{実稌方法}

\section{1. 試料}

25 歳から 54 歳の近畿在住主婦 25 名の協力を得て, 1 人 1 日食, 計 25 人分の陰䑅方式による調理食品（成 入女性対象) の提供を, 1986 年 7 月, 同 11 月及ひ 1987 年 7 月の計 3 回にわたり受けた。対象の主婦は, 第 1 回，第 2 回は 25 名之も同一人で，第 3 回目のみ 1 名の変更があった，試料の調製は，均質化に必要な水を 通宜添加して 1 日分全部をミキサーでホモジナイズし， 分析まで泠凍保存した．また，北海道江別市周边在住主 婦27名を対象とした陰嘻試料についても，地域差を調 差する目的で分析を行った。この試料は江別保健所で採 取後，国立衛生試験所でホモジナイス調製されたるので ある。 なお, 食品名之調理前重量は, 朝食, 昼食, おゃ つ及び夕食ことに詳細に記録した。

\section{2. 試薬及ひ方法}

試料 $50 \mathrm{~g}$ にアセトンと $n$-ヘキサンを加えて 2 回ホモ ジナイズ抽出し，冷却遠心分離後，有機溶媒層を分液漏 斗に移した。これに $2 \%$ 食塩水を添加し，へキサンに転 溶した後, 2 回水洗し $5 \mathrm{ml}$ に浱縮した. 祳樎液をフロリ ジルドライカラムクロマトグラフィーにより脱脂し，さ らにフロリジルウェットカラムクロマトグラフィーで精

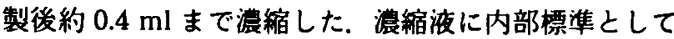
$\delta$ - $\mathrm{HCH}(1 \mathrm{ppm}, 100 \mu \mathrm{l})$ を加え GC/MS 用検液とした.

なお，前報4では内部標準に $0, p^{\prime}$-DDT を用いたが，一部 の試料で妨害ピークのため再度精製を必要とするなどや や煩雑のため手間取った，そこで今回，内部標準につい て再度検討を行い，マスフラグメント上で妨害ピークの ない $\delta$ - $\mathrm{HCH}$ を使用した。 分析方法及び使用した試薬， ホモジナイザー，質量分析計などの装置は，前却"と同様 である。測定は， $p, p^{\prime}$-DDT, $p, p^{\prime}$-DDE, hexachlorobenzene (以下 HCB と略す), $\gamma$-chlordene, heptachlor epoxide (以下 HCE と略す), trans-, cis-chlordane,oxychlordane, trans-, cis-nonachlor の 10 化合物について 行った.

3. SIMによる測定イオン $(m / z)$

$\operatorname{SIM}$ (マスフラグメントグラフィー) の測定イオンは, 以下の通りである.

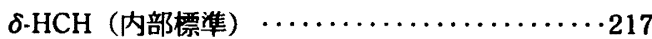

$p, p^{\prime}$-DDT $\ldots \ldots \ldots \ldots \ldots \ldots \ldots \ldots \ldots \ldots \ldots \ldots \ldots \ldots, 235,237$

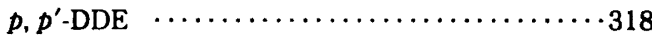

НСB $\cdots \ldots \ldots \ldots \ldots \ldots \ldots \ldots \ldots \ldots \ldots \ldots+286$

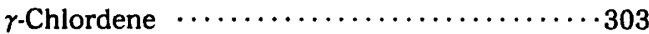

HCE $. \ldots \ldots \ldots \ldots \ldots \ldots \ldots \ldots \ldots \ldots, \ldots \ldots \ldots 35$

trans, cis-Chlordane $\ldots \ldots \ldots \ldots \ldots \ldots \ldots, 373$

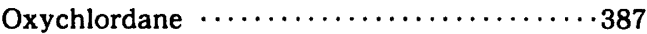

trans, cis-Nonachlor $\ldots \ldots \ldots \ldots \ldots \ldots \ldots, \ldots 07$

Table 1. Statistical Figures of Organochlorine Compounds in Daily Food for Women in Kinki District

\begin{tabular}{|c|c|c|c|c|c|c|c|c|c|}
\hline & & \multirow{2}{*}{$\begin{array}{c}\text { Age } \\
\text { (years) }\end{array}$} & \multirow{2}{*}{$\begin{array}{c}\text { Food } \\
\text { intake } \\
(g)\end{array}$} & \multirow{2}{*}{$\begin{array}{l}\text { Fish }^{\text {a) }} \\
\text { intake } \\
\text { (g) }\end{array}$} & \multicolumn{5}{|c|}{ Dietary intake of organochlorine compounds } \\
\hline & & & & & $\mathrm{CHL}^{\mathrm{b})}$ & HCE & $\begin{array}{c}\text { DDT } \\
(\mu \mathrm{g} / \text { day })\end{array}$ & DDE & $\mathrm{HCB}$ \\
\hline Kinki 1986/ 7 & $\begin{array}{l}\text { Mean } \\
\text { (S. D.) } \\
\text { Median }\end{array}$ & $\begin{array}{c}38.2 \\
(7.6) \\
38.0\end{array}$ & $\begin{array}{c}1864 \\
\left(\begin{array}{c}444) \\
1960\end{array}\right.\end{array}$ & $\begin{array}{c}18.6 \\
(31.3) \\
0\end{array}$ & $\begin{array}{c}2.21 \\
(2.44) \\
1.25\end{array}$ & $\begin{array}{c}0.26 \\
(0.37) \\
0.15\end{array}$ & $\begin{array}{c}0.71 \\
(1.21) \\
0.39\end{array}$ & $\begin{array}{c}0.99 \\
(1.59) \\
0.37\end{array}$ & $\begin{array}{c}0.23 \\
(0.15) \\
0.17\end{array}$ \\
\hline Kinki $1986 / 11$ & $\begin{array}{l}\text { Mean } \\
\text { (S. D.) } \\
\text { Median }\end{array}$ & $\begin{array}{c}38.6 \\
(7.9) \\
38.0\end{array}$ & $\begin{array}{c}1831 \\
(367) \\
1820\end{array}$ & $\begin{array}{c}19.8 \\
(39.3) \\
0\end{array}$ & $\begin{array}{c}1.98 \\
(3.40) \\
0.76\end{array}$ & $\begin{array}{c}0.19 \\
(0.37) \\
0.11\end{array}$ & $\begin{array}{c}1.08 \\
(2.22) \\
0.42\end{array}$ & $\begin{array}{c}1.27 \\
(2.56) \\
0.50\end{array}$ & $\begin{array}{c}0.12 \\
(0.06) \\
0.10\end{array}$ \\
\hline Kinki $1987 / 7$ & $\begin{array}{l}\text { Mean } \\
\text { (S.D.) } \\
\text { Median }\end{array}$ & $\begin{array}{c}39.4 \\
\left(\begin{array}{c}7.6) \\
39.0\end{array}\right.\end{array}$ & $\begin{array}{c}1891 \\
(409) \\
1955\end{array}$ & $\begin{array}{c}6.2 \\
(17.2) \\
0\end{array}$ & $\begin{array}{c}1.93 \\
(2.35) \\
0.82\end{array}$ & $\begin{array}{c}0.12 \\
(0.27) \\
0.04\end{array}$ & $\begin{array}{c}0.29 \\
(0.42) \\
0.17\end{array}$ & $\begin{array}{c}0.72 \\
(0.89) \\
0.40\end{array}$ & $\begin{array}{c}0.11 \\
(0.10) \\
0.09\end{array}$ \\
\hline
\end{tabular}

a): Marine products except shellfish, crab, octopus, shrimp, squid, dried bonito and fish paste products

b): Sum of chlordane compounds except $\mathrm{HCE}$ 


\section{耛果と考察}

\section{测定桔果の基礎統計量}

Table 1 に近幾在住主婦を対象に行った 3 回の調査結 果をまとめた. また, 参考のために, 有機塩素系化合物 の攝取㢆への寄与率が高いと思われる一部の魚介類の摂 取量を示した。なお，この摃取量は、これまで報告され

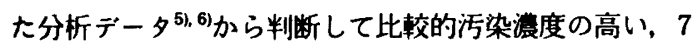
魚類 (ハマチ (Yellowtail yg.), サバ(Mackerel), アシ (Horse-mackerel), イワシ (Sardine), サワラ (Spanish mackerel), カマス (Barracuda), タチウオ (Hair-tail)) の みを技粋したものである.イカ (Squid), タコ (Octpus), カニ (Crab), エビ (Shrimp), 貝類及び魚肉ねり製品は, 污染レベルが低く摄取量への寄与も小さいと思われたの で, 除外した.

測定した 5 化合物群 (CHL は, HCE を除く 6 成分の 和）を平均値でみると, 総 CHL のみが第 1 第 3 回目 とも同じレベルで, 他の 4 化合物は第 1 , 第 2 回に比ベ て第 3 回目の湘定値がかなり低くなつた. 特に, HCE の 1987 年 7 月の平均値 $0.13 \mu \mathrm{g}$ は, 1986 年 7 月の半量で あった. その原因として, 魚介類摃取量が後者において 前者の約 1/3 と低かったことが考えられる. DDT 第 1, 第 2 回測定から第 3 回測定にかけて大幅に減少した が, その原因は, 前報4で DDT 化合物による高濃度污染 がサワラにみられることを述べたが, 今回の食䭒にはサ ワラが含まれなかったことによるものと考えられる。な お, HCE は technical CHL の主成分の一つである heptachlor の代謝産物で, 総 CHL に含まれるすのであ る.しかし，CHL が白アリ防除に使用される以前に, heptachlor は農薬として使われていたことから，食䬣 中の HCE がそのどちらに由来するのかが不明である. そのため, 今回の結果では HCE は総 CHL には加えな かった.これらの測定結果を中央値について, 前報 ${ }^{4}(6$ 人の協力者から 1 人 7 日分計 42 食の陰膳の提供を受け 分析）と比較すると，ややばらつきがあるものの，CHL を除いてほぼ同レベルであった．CHL 攝取量は，前報4 （平均値: $0.68 \mu \mathrm{g}$; 中央值 : $0.50 \mu \mathrm{g}$ ）に比べて，第 1 第 3 回測定ともに約 2 倍量であった. その原因を追求する 過程で, 本報の対象者の中に白アリ防除を行った家がよ り多いことが判明した。このことから, 散布した technical CHL が調理食品に吸着する可能性が推察された。こ の推論の詳細は後に述べる.今回行った陰膳方式は, 標 隼偏差の大きさから分かるように, データの変動がかな り大きい.これに対し，国民栄養調查の食品摄取量に個 別食品の分析値を乗じて求める積算法やマーケットバス ケット法は, 比較的精度の良い平均摄取量を求めること ができる. しかし，一方，得られるデータが平均值のみ で，個別の攝取量から生ずる情報を得ることはできな い. 陰膳方式で精度を求めるには, どの程度の試料を分 析したらよいのであろうか. 今回行った 3 回の全分析値
をもとに，母平均値からの調查平均のふれを $10 \%$ の変 動以内に納めるのに必要な試料数を試算 $(p<0.05) し て$ みた. その結果, 変動係数の最も小さかった $\mathrm{HCB}(0.152$ $\pm 0: 120 \mu \mathrm{g}, n=75)$ で 250 , 変動の最も大きかった DDT $(0.695 \pm 1.496, n=75)$ では 1835 もの試料を要する結果 となった. しかし，実際にこの数の試料を分析すること は不可能に近く，陰膳方式で調査する限り；真の平均摃 取量からのある程度の誤差は，否めないと言えよう. 今 回のように, 75 試料で行った場合の平均値の母平均に 対する誤差率は, HCBで $\pm 18 \%$, DDT で $\pm 49 \%$ 程度 である. Table 1 の 3 回の基礎統計量の変動は, その原 因の説明が明確にできるものを除いて、分析数不足から 生じたものと思われる. 調查期間が短いこともあり, 污 染の上昇あるいは低下とは考えにくい.

\section{摄取量の地域差}

近畿と北海道江別の調査結果について, 平均値の差の 検定 (student $t$-test) を行い Teble 2 に示した. $r$. Chlordene から $\Sigma$ (総) $\mathrm{CHL}$ まで CHLすへてに有意差 が認められた。 近幾の総 CHL 捸取量の平均値は江別の 約 3.5 倍で, 中央值でも約 2 倍の高値であった、HCE, DDT, DDE 及び HCB は, 江別の方が高いものもみられ るが, その原因は極めて高い数値が HCE とDDT で各 1 件（各々 $6.56 \mu \mathrm{g}, 15,93 \mu \mathrm{g}$ ）あったためで, 有意差は認 められなかった，従って，中央値で比較すると、これら の 4 化合物の摄取量は, 両地域でほぼ同じかまたは近䨀 の方がやや高いレベルであった. これらの結果は, DDT,

Table 2. Comparison of Daily Dietary Intakes of Organochlorines in Kinki and Ebetsu, Hokkaido

\begin{tabular}{|c|c|c|c|}
\hline & Kinki & \multicolumn{2}{|c|}{ Ebetsu } \\
\hline \multirow[t]{2}{*}{ Number of diet } & 75 & \multicolumn{2}{|c|}{27} \\
\hline & Mean (S.D.) & \multicolumn{2}{|c|}{ Mean (S.D.) } \\
\hline Age (years) & $38.8(7.6)$ & 38.9 & ( 5.9$)$ \\
\hline Food intake (g) & $1862^{* *}(403)$ & 2527 & (674) \\
\hline Fish intake (g) & $59.1 \quad(54.4)$ & 62.6 & (55.9) \\
\hline$\gamma$-Chlordene $(\mu \mathrm{g})$ & $0.48^{* *}(0.86)$ & 0.03 & $(0.03)$ \\
\hline trans-Chlordane $(\mu \mathrm{g})$ & $0.47 *(0.70)$ & 0.18 & $(0.25)$ \\
\hline cis-Chlordane $(\mu \mathrm{g})$ & $0.47^{*}(0.66)$ & 0.18 & $(0.13)$ \\
\hline Oxychlordane $(\mu g)$ & $0.03^{* *}(0.05)$ & 0.01 & $(0.01)$ \\
\hline trans-Nonachlor $(\mu \mathrm{g})$ & $0.50 * *(0.58)$ & 0.17 & $(0.16)$ \\
\hline cis-Nonachlor & $0.09 *(0.16)$ & 0.02 & (0.03) \\
\hline$\Sigma \mathrm{CHL}(\mu \mathrm{g})$ & $2.04^{* *}(2.74)$ & 0.59 & $(0.46)$ \\
\hline $\mathrm{HCE}(\mu \mathrm{g})$ & $0.19 \quad(0.34)$ & 0.48 & (1.27) \\
\hline DDT $(\mu \mathrm{g})$ & $0.70 \quad(1.50)$ & 0.91 & (3.01) \\
\hline DDE $(\mu \mathrm{g})$ & $0.99 \quad(1.80)$ & 0.45 & $(0.30)$ \\
\hline $\mathrm{HCB}(\mu \mathrm{g})$ & $0.15 \quad(0.12)$ & 0.14 & $(0.09)$ \\
\hline
\end{tabular}


Table 3. Correlation Coefficient between Dietary CHL and Fish Intakes ${ }^{\text {a) }}$

\begin{tabular}{cccc}
\hline & \multirow{2}{*}{ Overall } & \multicolumn{2}{c}{ Termite treatment } \\
\cline { 3 - 4 } & & Untreated & Treated \\
\hline $\mathrm{N}^{\text {b) }}$ & 75 & 45 & 30 \\
\hline $\mathrm{CCHL}$ & 0.194 & 0.462 & -0.003 \\
$\mathrm{HCE}$ & 0.226 & 0.389 & 0.030 \\
$\mathrm{DDT}$ & 0.480 & 0.524 & 0.427 \\
$\mathrm{DDE}$ & 0.477 & 0.494 & 0.500 \\
$\mathrm{HCB}$ & 0.458 & 0.456 & 0.425 \\
\hline
\end{tabular}

a): Marine products except shellfish, crab, octopus, shrimp, squid, dried bonito and fish paste products

b): Correlation coefficients were calculated for dietary samples collected in Kinki district.

DDE，HCB 及び HCE が，使用禁止後の 15 年以上を経 て污染の低下 ${ }^{3 h}$ 7) と共に全国にほぼ均一に拡散したのに 対して, CHL は禁止後間もないことから, 近畿と江別の 使用量の差がそのまま摄取量の差に反映したことを示唆 するものである.

\section{魚介類の掫取量への奇与率}

一般的に有機塩素系化合物のヒト污染源としては，魚 介類が最も寄与率が高いことが, 多くの調查研究で確認

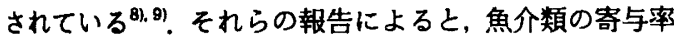
は7 割〜10 割を占めている. 日本では, DDT, $\mathrm{HCH}$, PCB などの主な有機塩素系化合物の使用が禁止になっ て既に 15 年以上を経過しており、PCBでは污染の総量 がほとんど海洋に集中し，また $\mathrm{HCH} ゃ \mathrm{DDT} な と ゙$ 畑 を中心に散分された農薬についても，污染が陸上から海 洋に徐々に移行していることが報告されている ${ }^{10}$. これ らの研究結果を考虑すれは，現時点における魚介類の七 ト污染への寄与率は, 文献值州よりも高く, さらに, 今 後より高くなることが予想される。，一方，CHLは 1986 年まで使用されており，また，使用場所が床下を中心と する家屋内であったことから，上述の PCB, DDTなどと はやや異なったパターンでヒトを污染することが考えら れる. 前報で CHL も PCB や DDT などと同様に, 食䀦 由来污染の原因は魚介類が中心であることを示唆する解

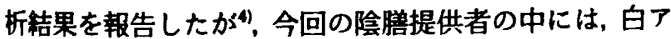
リ防除を行った家屋に居住している者が多い，そこで再 度，魚介類摄取量之污染物質摄取量との相関関係を検討 したななお，前章であ述べたように，本解析ではイカ， 夕コ, カ二, エビ, 貝類及び魚肉和り製品は除外して計 算した。

近幾で行った 3 回の調査 75 例全体では，前報と同様 に，白アリ防除をしていないと 45 例で 5 化合物すべて に対して有意な相関か認められた。一方, 防除家屋に居
Table 4. Influence of Termite Treatment to Dietary CHL Intake

\begin{tabular}{|c|c|c|c|}
\hline & \multicolumn{3}{|c|}{ Termite treatment } \\
\hline & \multicolumn{2}{|c|}{ Untreated } & Treated \\
\hline \multirow[t]{2}{*}{ Number of samples } & \multicolumn{2}{|c|}{45} & 30 \\
\hline & \multicolumn{2}{|c|}{ Mean (S.D.) } & Mean (S.D.) \\
\hline Years after treatment & 0 & -1 & $(1.9)$ \\
\hline$\gamma$-Chlordane $(\mu \mathrm{g})$ & 0.15 & $(0.10)$ & $0.96^{* *}(1.21)$ \\
\hline trans-Chlordane $(\mu \mathrm{g})$ & 0.17 & $(0.15)$ & $0.92^{* *}(0.92)$ \\
\hline cis-Chlordane $(\mu \mathrm{g})$ & 0.17 & $(0.22)$ & $0.92^{* *}(0.83)$ \\
\hline Oxychlordane $(\mu g)$ & 0.03 & $(0.04)$ & $0.05^{*}(0.06)$ \\
\hline trans-Nonachlor $(\mu \mathrm{g})$ & 0.25 & $(0.25)$ & $0.88^{* *}(0.72)$ \\
\hline cis-Nonachlor $(\mu \mathrm{g})$ & 0.04 & $(0.07)$ & $0.17^{* *}(0.21)$ \\
\hline$\Sigma \mathrm{CHL}(\mu \mathrm{g})$ & 0.80 & $(0.68)$ & $3.90^{* *}(3.53)$ \\
\hline $\mathrm{HCE}(\mu \mathrm{g})$ & 0.18 & $(0.34)$ & $0.21 \quad(0.34)$ \\
\hline DDT $(\mu g)$ & 0.59 & $(1.55)$ & $0.85 \quad(1.43)$ \\
\hline $\mathrm{DDE}(\mu \mathrm{g})$ & 0.92 & $(1.99)$ & $1.09 \quad(1.52)$ \\
\hline $\mathrm{HCB}(\mu \mathrm{g})$ & 0.14 & $(0.12)$ & $0.18 \quad(0.12)$ \\
\hline
\end{tabular}

*: $p<0.05$ **: $p<0.01$

住している 30 例では, DDT, DDE 及び HCB の 3 化合 物に対しては相関係数は有意であったが，総 $\mathrm{CHL}$ と CHL 類の HCE に対しては相関が認められなかった (Table 3).これらの結果から, CHL のヒト污染源は, 防 除家屋居住者を除く一般家庭では PCB や DDT と同様 にやはり魚介類が中心であるが，防除家庭では魚介類以 外の污染経路が存在することが推測された，実際に，防 除群の個々の測定値と食䭒内容を調へてみると, CHL 摄取量が平均の数倍であるにも関わらず，魚介類をはと んど含んでいない陰膡が多数あった。 なお，総 $\mathrm{CHL}$ 搨 取量が $2 \mu \mathrm{g}$ をこえる陰膳が 21 例あったが，その中で白 アリ防除をしていない対象者は 2 例であった.

\section{白アリ防除によるCHL掞取岳の上昇}

そこで，防除家屋と非防除家屋の陰膳について污染物 摂取量の平均值の差の検定を行った (Table 4)。 その結 果，防除を行って平均 4.2 年を経過した延べ 30 家庭の CHL 摄取量は総 CHL で対照の 4.9 倍高く， 6 成分すへ てに有意差が認められた。 また, CHL6成分のパターン も両者間で異なっており，防除群では technical CHL の 主成分でありながら魚類を含む生物体内で比较的速やか に代謝排泄される $\gamma$-chlordene, trans-, cis-chlordane の 相対含有率がやや高かった。このことは，防除家屋内で は散布 CHL の暴露が継続していることを示唆するもの である. HCE, DDT, DDE 及び HCB もやや高かったが 有意差は認められず，むしろ，その原因は，魚介摃取量 $(24.0 \pm 34.6 \mathrm{~g})$ が対照 $(8.8 \pm 26.8 \mathrm{~g})$ に対して多かったこ とによると思われる．防除群の摂取 CHL の成分バター 


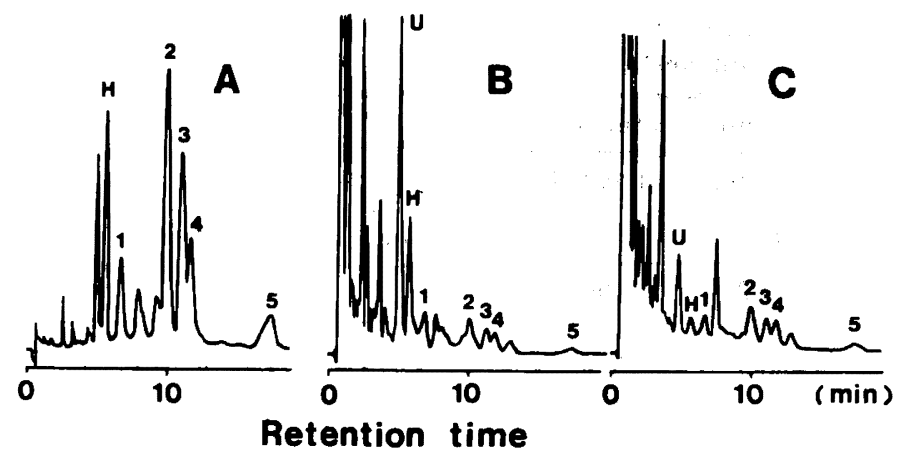

Fig. 1. Gas chromatograms of CHLs in technical chlordane and diet samples whose houses were treated for termite control.

Shimadzu GC-6A with ECD detector fitted with a glass column $(2 \mathrm{~m} \times 2 \mathrm{~mm})$ packed with $2 \% \mathrm{OV}-1$ was used.

A: technical chlordane $(0.415 \mathrm{ng})$; B: diet sample taken 1.5 years after the treatment (total $\mathrm{CHL}=16.7 \mu \mathrm{g}$ or $21.7 \mu \mathrm{g}$ including heptachlor); $\mathrm{C}$ : diet sample taken 7.5 years after the treatment (total $\mathrm{CHL}=5.6 \mu \mathrm{g}$ or $6.0 \mu \mathrm{g}$ including heptachlor); $\mathrm{U}$ : undetermined; $\mathrm{H}$ : heptachlor; 1: $\gamma$-chlordene; 2: trans-chlordane, 3: cis-chlordane; 4: trans-nonachlor; 5: cis-nonachlor

ンは、これ以外にも大きな特徵を有する. Fig. 1 に防除 後 1.5 年 (B) 及び 7.5 年 (C) を経過した家庭で調理した 食慨中の CHL 成分のガスクロマトグラムを示した。 な お， $\mathrm{B}$ は今回の測定の中で最高値であった．これらの成 分の中で, heptachlor (Fig. 1 の H) は非防除家庭では 通常検出されない，今回の測定に heptachlor を除外し たのはその理由による.この 2 例について別途 heptachlor を測定し総 CHL に加えたところ，Bでは $16.7 \mu \mathrm{g}$ が $21.7 \mu \mathrm{g}$ (約 $30 \%$ 上昇), C は $5.6 \mu \mathrm{g}$ が $6.0 \mu \mathrm{g}$ (約 7\% 上昇)になった. さらに, heptachlor 以外にも CHL 成分が検出されたが (Fig. 1 のU), 標隼物質がないので 定量できなかった. 従って, 防除家庭では実質的な CHL 攝取量は, 測定値よりも数\%から 3 割程度高いものと思 われる.このように, ガスクロマトグラム上でリテンシ ョンタイムの比較的小さい成分を多く含む CHLパター ンは，防除家屋の空気中 CHL でも钼察されており ${ }^{11}$, 上述したように散布した technical CHL 成分の内, 揮発 しやすい成分を多く含む組成の CHL 暴蕗が継続してい ることが推測できる.

\section{まとめ}

CHL のヒト污染経路を明らかにする目的で, 食品由 来の摄取量調查を行った。 近幾在住主婦 25 名 3 日分計 75 食, 及び北海道江別市周辺在住主婦 25 名各 1 日分の 食餉について，CHL 6 成分之他の有機塩素系化合物 4 成分を測定した，近幾の総 $\mathrm{CHL}$ の平均摄取量は，約 2 $\mu \mathrm{g}$ で DDT, DDE, HCB より高かった. 江別市の掫取量 と比较すると, CHL 6 成分のみ近維の方が有意に高かっ た. 近畿の CHL と魚介類の摄取年の相関を解析したと ころ，CHL 防除をしていない家庭では全測定化合物に
有意な相関がみられ，これまでの報告と同じ㑯向を示し たが，防除家庭では CHL 成分の相関が認められなかっ た. 防除群と非防除群の摄取量の平均値の差の検定を行 ったところ，DDT，DDE， HCB 及び HCE は大差がなか ったが、CHL 6 成分はすべて防除群の方が有意に高かっ た.さらに, 防除群の摄取 CHL の成分パターンは, technical CHL の内，揮発しやすい成分を相対的に多く 食品に吸着したことを示唆する特徴的な組成を呈した. これらの結果から，CHLのヒト污染源は，やはり魚介類 が中心であるが, CHL 防除家庭では魚介類以外の食品 が CHL 摄取に大きく関与していることが推測できた. なお，防除家庭の CHL 摂取量が有意に高くなる原因究 明のため，幾つかのモデル実験を行ったところ，CHLを 含んだェアロソルが床下から上昇し，流し下の米びつ内 のコメに吸着することが分かった．そのモデル実験の詳 細については，次報で述べる。

\section{端 辞}

本研究は，環境庁公害防止等試験研究費による「㻴境 污染物質の摄取総量に対する経路別寄与率の評価方法磪 立に関する研究」の分担研究として行ったものである. 終始御指营頂いた研究班長の国立公衅衛生院衙生薬学部 藤田昌彦部長及び北海道の陰䐣試料を調製された江別保 健所，国立衛生試験所の関係諸氏に深謝します．本研究 の一部は, 第 53 回日本食品衙生学会 (1987 年, 神戸) で発表したものである.

\section{女 蒚}

1) 立川 凉：公害と日本の科学 8,5 9 (1974).

2) 田辺信介：浻岸海洋研究ノート 19,9〜19 (1981).

3）小西良昌，薬師寺䅪，西宗高弘，国田信治：大阪将立公筩 
研所報. 食品術生編. 20, 35 42 (1989).

4) 田口华三，菜師寺和，小西良昌，西宗高弘，田中原一：食 術誌、30, 562 533 (1989).

5) 内山 充: 食品術生研究 33, 7 16 (1983).

6）桑原克義，松本比佐志，村上保行，西宗高弘，末木㹂二， 田中凉一，整本 隆：食衛誌.30, 359～366 (1989).

7) Global Environmental Monitoring System: "Summary and Assessment of Data Received From the FAO/ WHO Collaborating Centres for Food Contamination Monitoring" p. 11 44 (1982), National Food Administration, Uppsala.
8) Watanabe, I., Yakushiji, T., Kuwabara, K., Yoshida, S., Maeda, K., Kashimoto, T., Koyama, K., Kunita, N.: Arch. Environ. Contam. Toxicol. 8, 67 75 (1979).

9) Jelinek, C., Corneliussen, P.E.: "National Conference on Polychlorinated Biphenyls (Nov. 19 21, 1975, Chicago, Illinois)" p. 147 (1976), US Environmental Protection Agency, Office of Toxic Substance, Washington, D.C. (1981)

10）田辺信介，立川 涼: 㻴境技術. 13, 383 388 (1984).

11）立成文彦，浅川富美雪，真鍋芳樹，後藤敦，中鴄泰知： 日本公術誌. 6, 302 308 (1987). 